\title{
Cooling of high power LED chip by boiling on the longitudinal finned surfaces
}

\author{
Evgeniy Shatskiya \\ Kutateladze Institute of Thermophysics SB RAS, Lavrent'ev av. 1, Novosibirsk, 630090, Russia \\ Novosibirsk State University, 630090 Novosibirsk, Russia
}

\begin{abstract}
In this work, we have created a new experimental setup for studying heat transfer from a local heat source. The boiling heat transfer on the local heaters with a diameter of 5 and $1 \mathrm{~mm}$ has been investigated. It is shown that on the finned surfaces the overheating relative to the saturation temperature in comparison with a smooth surface decreases up to three times for the heater with a diameter of $5 \mathrm{~mm}$. There is up to two times increase in heat transfer coefficient on finned surfaces as compared to the smooth ones. For finned surfaces on the heater with a diameter of $1 \mathrm{~mm}$ the surface overheating relative to the saturation temperature decreases in four times. More than three times increase is observed for the heat transfer coefficient on finned surfaces as compared to the smooth ones.
\end{abstract}

\section{Introduction}

The future of a number of sectors of the economy is linked with the technology of solid-state light sources and one of the main characteristics of uptime is the removal of heat. Study of the evaporation mechanism on the surfaces of small size was started in [1]. The main objective was to study the temperature fields of the heating surface and liquid, and to study conditions for the formation and existence of a thin film of liquid at the base of the vapor bubble. In this work, as in the follow-up, dedicated to the study of a single center of vaporization [2], the heat flux limited with value at which there is a steady generation of a single center of evaporation, that is relatively modest values. A review of studies on heat transfer during vaporization at the surface of the small size is contained in [3].

Cooling of heat-emitting surfaces in different technological applications is an important problem, which can be solved by such processes as film flows [4, 5], etc. In our days the problem of creating an effective compact cooling system for powerful LEDs whose efficiency and durability are highly dependent on the efficiency of the power removal remains unsolved.

Study of evaporation mechanism on the surfaces of small size (SSS) was started in [6]. Heat transfer at boiling of dielectric liquids on the heaters of small size in the sunk vertical channels was studied in [7]. A review of works on heat transfer at evaporation on SSS may be found in [3]. In the literature, there is a dependencies for the critical heat flux density for each type of SSS, having the general form:

\footnotetext{
${ }^{\text {a }}$ Corresponding author : shatskiy.itp@gmail.com
} 


$$
q_{c r} / q_{c r \infty}=k\left(d_{s} / l_{\sigma}\right)^{n}
$$

but differing in correlation multipliers; and $\mathrm{d}_{\mathrm{s}}$ is the diameter of the heating surface. Here

$$
q_{c r o s}=0.13 r_{l v} \rho_{v}\left(\frac{\sigma\left(\rho-\rho_{v}\right) g}{\rho_{v}^{2}}\right)^{0.25}
$$

$\mathrm{r}_{\mathrm{lv}}$ is the latent heat of vaporization, $\rho_{\mathrm{v}}$ is the vapor density, $\rho$ is the fluid density, $\sigma$ is the surface tension, and $\mathrm{g}$ is the gravity acceleration.

For locally heated horizontal plates $\mathrm{k}=3.4, \mathrm{n}=-0.5$ [3], for horizontal cylinders $\mathrm{k}=1.4$ [8], and for spheres $k=2.5$ [8]. The reason for such significant effect of the size of SSS on $\mathrm{q}_{\mathrm{cr}}$ is connected with the feature of hydrodynamic situation that occurs around the surface of small size (SSS).

The aim of the present work is studing of pool boiling of water on the surfaces with different geometry.

\section{Experimental setup}

To study the heat transfer processes that occur at boiling on the longitudinal finned surfaces, a new experimental setup was created. Schematic diagram of the experimental setup is shown in Fig. 1.

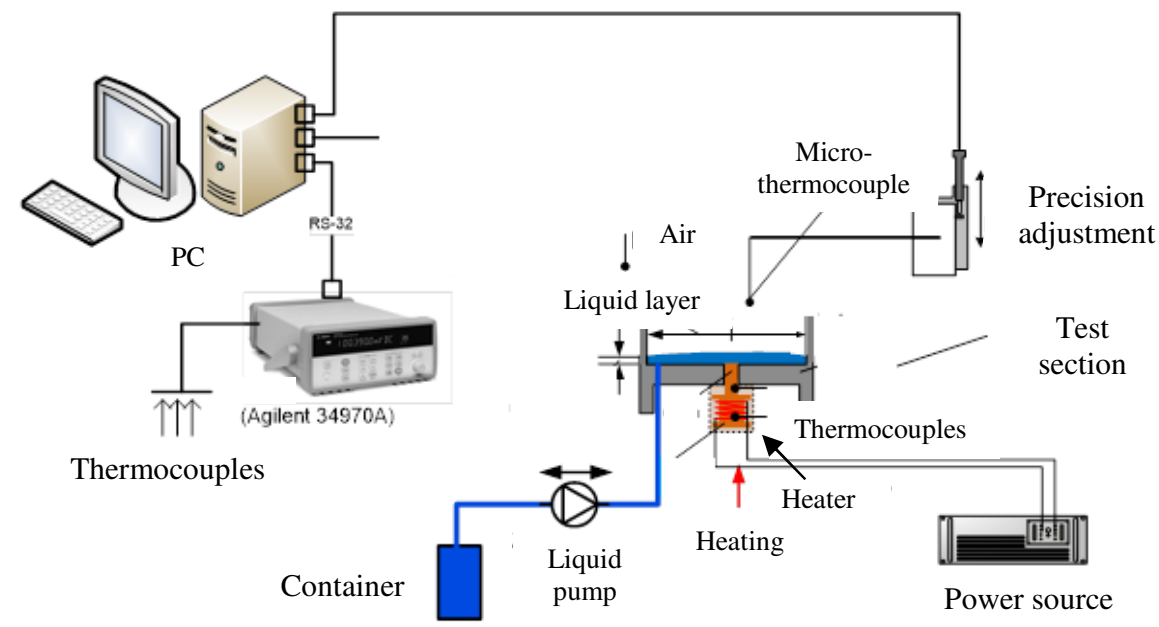

Figure 1. - Scheme of experimental setup.

The test section is a PTFE cilindeer with diameter $28 \mathrm{~mm}$. The working fluid (distilled water) is supplied to the test section using a peristaltic pump, where a horizontal layer of liquid is formed. The thickness of the liquid layer is controled by the amount of liquid (the geometry of test section is known) and varies depending on the operating parameters of the experiment $(20-50 \mathrm{~mm})$. In the center of the test section there is a local heating performed by a heater. The heating element is made of brass with a round head with a diameter of $1 \mathrm{~mm}$ and $5 \mathrm{~mm}$. The tip of the core tightly inserted into the base. The source of heat is a nichrome tape wound on the shank of the core. In order to minimize heat losses, the heating element was carefully insulated. The fiberglass was used as a heat insulator, which was wound in several layers around the core of the heating element. It was estimated that the whole incoming power transferred to the liquid and heat losses did not exceed 20\% [9]. 
To intensify the heat transfer from the heater surface to the liquid the surface of the heater $\mathrm{D}=5$ mm was milled with radial grooves (Fig. 3). For heater with diameter $1 \mathrm{~mm}$ special headers have been developed which also have been milled with grooves (Fig. 2). Heaters parameters are shown in Table 1, and the photographs in Figs. 2, 3.

Table 1. Parameters of the heaters.

\begin{tabular}{|l|l|l|}
\hline Diameter of the heater, $\mathrm{mm}$ & Number of fins & Surface area, $\mathrm{mm}^{2}$ \\
\hline 1 & 0 (smooth surface) & 78,5 \\
\hline 1 & 20 (small finns) & 277,4 \\
\hline 1 & 30 (large finns) & 360 \\
\hline 5 & 0 (smooth surface) & 19,6 \\
\hline 5 & 16 & 248,6 \\
\hline
\end{tabular}

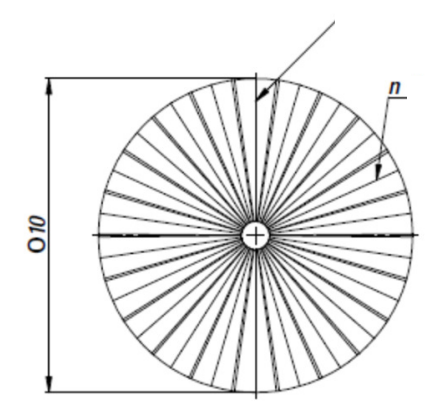

A

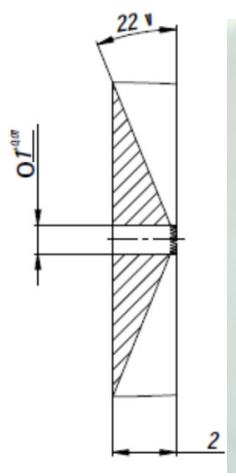

2

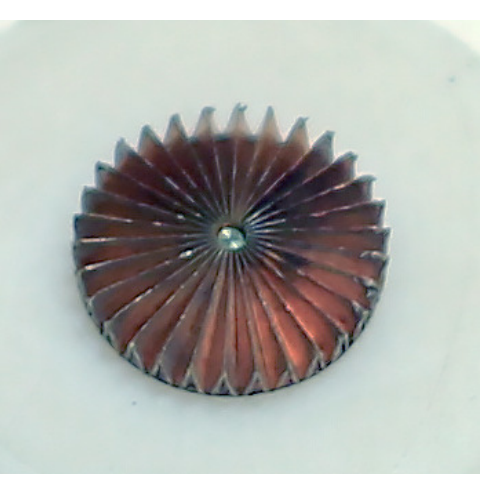

B

Figure 2. Drawing of the heater header for $\mathrm{D}=1 \mathrm{~mm}(\mathrm{~A})$ and photo (B).

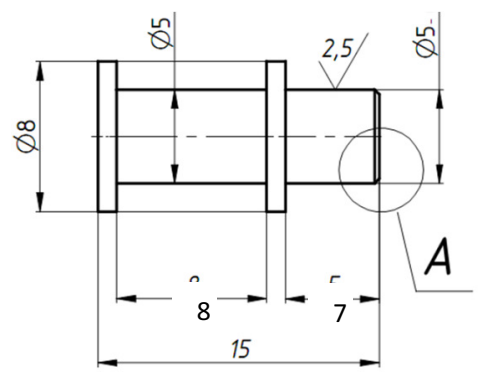

A
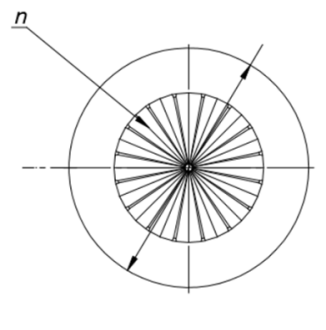

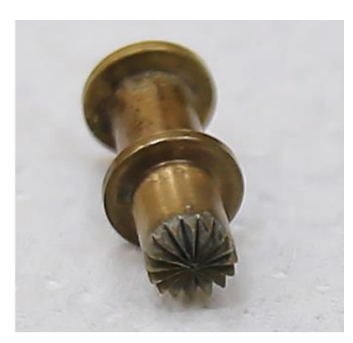

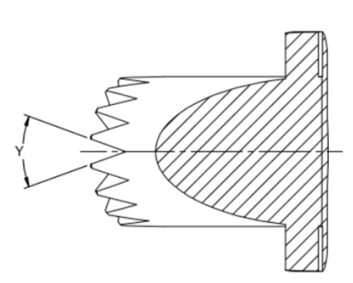

B

C

Figure 3. Drawing the heater $\mathrm{D}=1 \mathrm{~mm}(\mathrm{~A})$ smooth surface (B) finned surface, $(\mathrm{C})$ photo. 
The power of the heating element is controlled by the power source. The temperature of the heater (at the interface with the liquid) and the fluid is measured by a number of thermocouples. The data from thermocouples is collected using data acquisition system, and the temperature measurement precision is $0.1{ }^{0} \mathrm{C}$.

\section{Results and discussion}

Curves of boiling for heaters with $\mathrm{D}=5$ and $1 \mathrm{~mm}$ on a smooth and finned surfaces are presented (Figs. 4 and 5). It was found that the boiling curves for the finned surfaces are higher than smooth. Experiments on the heaters $D=5 \mathrm{~mm}$ with a smooth and finned surfaces showed that overheating on the finned surfaces is three times smaller (Fig. 4). And the heat transfer coefficient increases up to two times on the finned surface compared with the smooth.

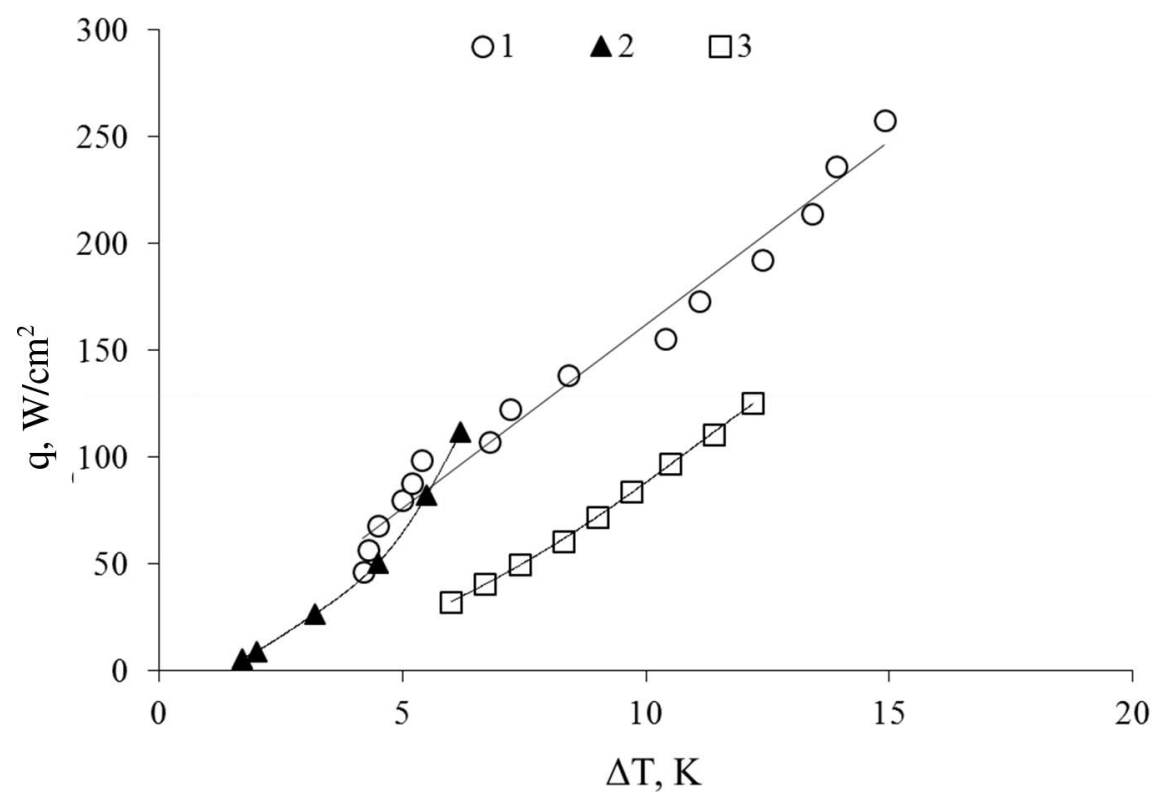

Figure 4. The dependence of the heat flux from the temperature difference for the heater for $\mathrm{D}=$ $5 \mathrm{~mm}$. 1 - large fins, 2 - small fins 3 - smooth surface.

Registration of heat transfer crisis was carried out by the thermocouples at the moment of instantaneous growth of temperature on the heater. The crisis of heat transfer has been registered on the heater with large fins (Fig. 4) and amounted to $256 \mathrm{~W} / \mathrm{cm}^{2}$.

The studies of heat transfer during boiling on a heater with a diameter of $1 \mathrm{~mm}$ are shown on Fig. 5 . It should be noted that the heat flux density was calculated using the area of the heater excluding the header. On the smooth surface overheating temperature reached about $200 \mathrm{C}$. The heat flux density before the heat transfer crisis reaches $900 \mathrm{~W} / \mathrm{cm}^{2}$. 


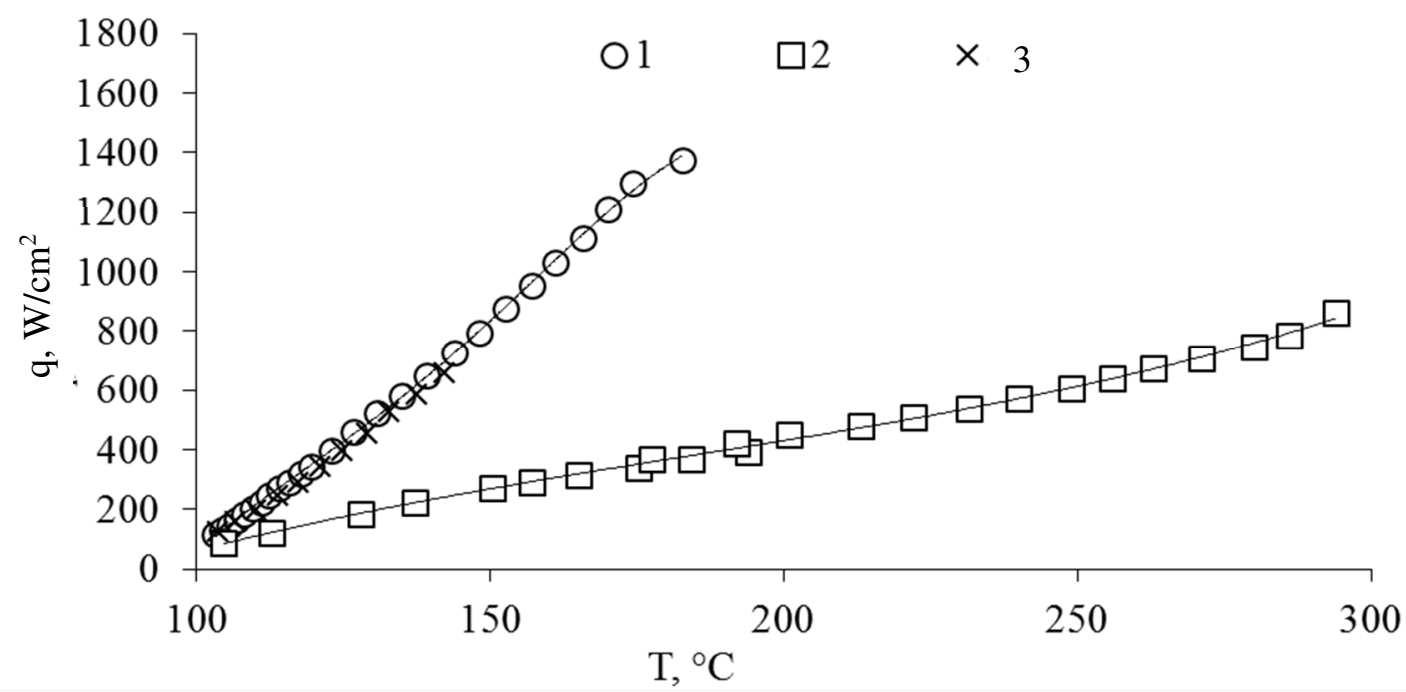

Figure 5. Dependence of the heat flux density from the temperature of the heater with a diameter $\mathrm{D}=1 \mathrm{~mm}$. 1 - head with large fins, 2 - smooth surface, 3 - head with small fins.

On the finned surfaces overheating relative to saturation temperature decreases up to four times. More than three times increases the heat transfer coefficient on the finned surface compared with the smooth. It should be noted that the type of finning has no significant effect on the boiling curve. As a result of the experimental work the density of heat flux reached $1400 \mathrm{~W} / \mathrm{cm}^{2}$.

In this study, we carried out experiments for the conditions of a large volume of fluid (thickness of the layer $>10 \mathrm{~mm}$ ) and maintaining the temperature of the fluid at saturation temperature. It was found that radial fining of the heater surface may lead to significant increase in critical heat flux density compared to the smooth one.

The work was supported by the RF Ministry of Education and Science (Agreement No. 14.604.21.0053, project ID RFMEFI60414X0053).

\section{References}

1. Moor F. D., Mesler R. B. AIChE Journal 7 (1961)

2. Borisov V. Z., Kirillov P. L. Journal of Engineering Physics and Thermophysics 28, 910 (1970)

3. Tolubinskiy, V.I., Antonenko, V.A., Kudritskiy, G.R., Ostrovskiy, Yu.N Industrial Heat Engineering 9 (1987)

4. Chinnov E. A. Journal of Heat Transfer 138 (2016)

5. Kabov O.A., Zaitsev D.V., Cheverda V.V. and Bar-Cohen A. Experimental Thermal and Fluid Science 35, 825 (2011)

6. Moor F. D., Mesler R. B. AIChE Journal 7 (1961)

7. Chinnov E.A., Dyatlov A.V., Kravchenko D.N. Siberian Physico-Technical Journal 5 (1992)

8. Linard D., Dir B. Teploperedacha C 2 (1973).

9. Yu. V. Lyulin, S. E. Spesivtsev, I. V. Marchuk and O. A. Kabov. Technical Physics Letters 41 (2015) 